\title{
Enhancing Students' Mental Models of Chemical Equilibrium Through Argumentation within Model-based Learning
}

\author{
Anupong Praisri and Chatree Faikhamta \\ Department of Education, Faculty of Education, \\ Kasetsart University, Thailand \\ https:// orcid.org/0000-0003-4396-1015 \\ https://orcid.org/0000-0001-7364-9140
}

\begin{abstract}
The purpose of this study is to investigate how students develop their mental models of chemical equilibrium through Argumentation within Model-based learning (AMBL). This qualitative research methodology draws upon a pre-post chemical equilibrium mental models survey, teacher's logs, classroom observations, and students' reflective diaries. The participants, purposively selected, were 29 grade 11 students. Data were analysed via qualitative methods, namely categorizing, comparing, and concluding. The research findings reveal that AMBL could develop students' tentative mental models into scientific models, particularly on the topics of dynamic equilibrium and reversible reactions. Key ideas for enhancing students' mental models include: providing students with opportunities to use evidence and justification in order to develop their mental models into scientific models; the suggested use of several media to represent particles at the microscopic level; and using driving questions to help students modify their models and link their understanding of both the macroscopic and microscopic levels through the modelling process. The study recommends the need for more emphasis on the role of argumentation in the modelling process.
\end{abstract}

Keywords: Mental Models; Model-based Learning; Argumentation; Chemical Equilibrium

\section{Introduction}

Chemical equilibrium is one of the key concepts in chemistry, and for several decades efforts have been made to help students understand this concept. However, it has been found that most students still have naïve conceptualizations of it (Van Driel \& Gräber, 2002; Hackling \& Garnett, 2007; Özmen, 2008; Karpudewan et al., 2015). Because it is related to the study of invisible matter representation, chemical equilibrium is classified as abstract content that is 
difficult for students to understand (Kousathana \& Tsaparlis, 2002; Akin \& Uzuntiryaki-Kondakci, 2018). For instance, students sometimes perceive that chemical equilibrium would have a complete forward reaction before a reverse reaction and that system equilibrium would be unchanged (Yakmaci-Guzel, 2013). Additionally, students have believed alternative concepts, such as the idea that if temperature is stable, adding a product substance would increase the equilibrium constant, or that a higher temperature would increase the products, disregarding whether the reaction was endothermic or exothermic (Voska \& Heikkinen, 2000; Kousathana \& Tsaparlis, 2002). As a result, the students could not explain the matter's behaviour at the particulate or sub-microscopic level. This indicates that encouraging students to comprehend only the concepts in forming their ideas may not be enough. Research has shown that learning with a variety of representations is vital to enhance students' conceptions in chemistry, especially in linking the three levels of representation (macroscopic, submicroscopic, and symbolic) (Taber, 2013; Sanchez, 2018; Schwedler \& Kaldewey, 2020; Gkitzia, Salta \& Tzougraki, 2020).

Nevertheless, chemistry educators expect that students will be able to explain three levels of representation (Johnstone, 1993; Taber, 2013) to explain how such matter behaviour happened, progressing from the macroscopic level to the microscopic level. To communicate for better understanding, the two levels of change should be linked with a symbolic level, such as a chemical equation. The explanation for these three levels is regarded as the model or conceptual representation created by chemists to clarify chemical phenomena (Justi \& Gilbert, 2002). Thus, constituting models usually commences with chemists observing chemical phenomena and attempting to explain phenomena by creating the simplest models-MMs, or representations which are specific models for individual creators as a part of the knowledge lying within them (Gilbert, 2005; Nersessian, 2010; Bongers et al., 2019). The teachers could perceive misaligned understanding from the students' expression of their MMs (Harrison \& Treagust, 1996; Coll \& Taylor, 2002; Taber, 2017).

For more than three decades, a variety of research has been conducted on developing students' MM (Maia \& Justi, 2009). Taylor, Barker, and Jones (2003) suggested that building mental models is a development process in which learners should be provided opportunities to articulate their mental models, clarifying what scientists mean by 'models'; making their mental models intelligible; repeatedly critiquing the scientists' mental models to enhance their plausibility; using the scientists' mental model to solve related problems, thus enhancing its efficacy; and defending the scientists' mental model, thus further enhancing its fruitfulness. Based on these ideas, researchers have suggested model-based learning (MBL) (Coll \& Lajium, 2011; Khan, 2011; Maia \& Justi, 2009; Markauskaite et al., 2020) as a strategy to engage students' modelling process. Some research studies have developed learning about chemical equilibrium through model-based instruction (Maia \& Justi, 2009) using the model of modelling diagram (MMD). Their findings revealed that this technique could develop students' visualization and representation skills. Such learning strategies 
affected the students - changing their concepts or developing other learning skills - as they enjoyed studying and truly understood chemical equilibrium.

However, Giere (2001) stated that, while the models in this world cannot completely explain phenomena, it could be said that we have evidence and reasons to create models that explain the phenomena better. So, in modelling, a rebuttal process is required based on the explanation with empirical evidence. Generally, the rebuttal process occurs when evaluating the congruence of the models and experiments. The rebuttal process should not only emphasize the model evaluation (Mendonca \& Justi, 2013) but should also focus on every step of the modelling as the driver for the model to be more complete. Scientific argumentation is the process of promoting student creation of scientific explanations by generating claims based on evidence-based explanations (Jime 'nez-Aleixandre \& Erduran, 2007; Sampson \& Clark, 2009). This evidence could be empirical evidence or scientific knowledge, and such a process occurs in the science instruction process (Faikhamta, 2016) and the modelling process. For instance, an argument could start from creation of the MM, such as a teacher asking students why they drew an atomic model as a solid sphere. The students would provide different reasons in attempt to validate their claim depending on different reasons, depending on their existing knowledge.

To test the model, an argument would emerge when the students tested the congruence of the created models with empirical evidence (Passmore \& Svoboda, 2012). The students would reason with empirical evidence to try to confirm their claims, and they would try to convince others to believe their models or believe how the new models were better than the old ones. Therefore, if the rebuttal process were added in every process of model-based learning management, the students' MMs would be more similar to the scientific models (i.e. more complete).

As noted above, during the modelling process the students relied on the rebuttal process to promote their MMs in accordance with the scientific models. From the literature, guidelines for model-based learning together with the rebuttal process were few, indicating a gap in the research. To fill this research gap, we examined whether and how Argumentation within Model-based Learning (AMBL) would help students develop their MMs of chemical equilibrium. The objective of this research was to study, through the use of two research questions, the characteristics of AMBL to develop the MMs of students concerning chemical equilibrium:

1. What is the student's MM of chemical equilibrium like during AMBL?

2. In what ways did AMBL enhance the MMs of chemical equilibrium of students?

\section{Conceptual Framework}

The conceptual frameworks of this study are mental modelling and three levels of representation, and argumentation within model-based learning. These two frameworks underpin the social constructivist view of learning (Leach \& Scott, 2003), which is used to explain how students learn to participate in modelling and scientific argumentation in the classroom. Science learning involves the processes 
of students' social interactions and their personal internalization of the ideas and language used to explain the natural phenomenon.

Mental modelling and three levels of representation

Due to its study of matter and representation, the content of chemistry is mostly abstract. Chemists explain three levels of representation: macroscopic, microscopic, and symbolic (Johnstone, 1993; Taber, 2013; Cheng \& Lin, 2019). An explanation of the three levels of representation is regarded as a model, or MM, created by chemists to explain chemical phenomena (Justi \& Gilbert, 2002). The models are presented in different forms, such as figures, abstract objects, and chemical equations. The MM is the model - or pictures in the brain - along with the unique characteristics of the person who created it as a part of their underlying knowledge. This is regarded as a personal model for explaining chemical phenomena (Gilbert, 2005; Nersessian, 2010; Bongers et al., 2019). Each person has a different MM. If that MM is surveyed and inspected until it is accepted by the scientific community, it will be developed into a scientific model that represents the phenomenon correctly, precisely, and completely (Gilbert et al., 2000; Van Der Valka et al., 2007; Cheng \& Lin, 2019). For the MM of chemical equilibrium, chemists often explain representation on three levels and give examples of concepts about reversible reactions. They begin by observing visible phenomena, such as when a solution's colour alternates between pink and dark rich blue when a solution of cobalt (II) sulphate and hydrochloric acid is cooled and heated. After that, they create a model at the microscopic level to explain the behaviour of the representation. That is, the particles of substrates reacted, the products were generated, and the particles of the products reacted and reversed to become the substrates. Nevertheless, in the reaction, the particles of the substrates and the products would remain for forward reaction and reverse reaction. To communicate for better understanding, a representation at two levels would be identified with chemical symbols: a chemical equation with an arrow pointing forward and backward to show reversible reactions, as displayed in Figure 1.

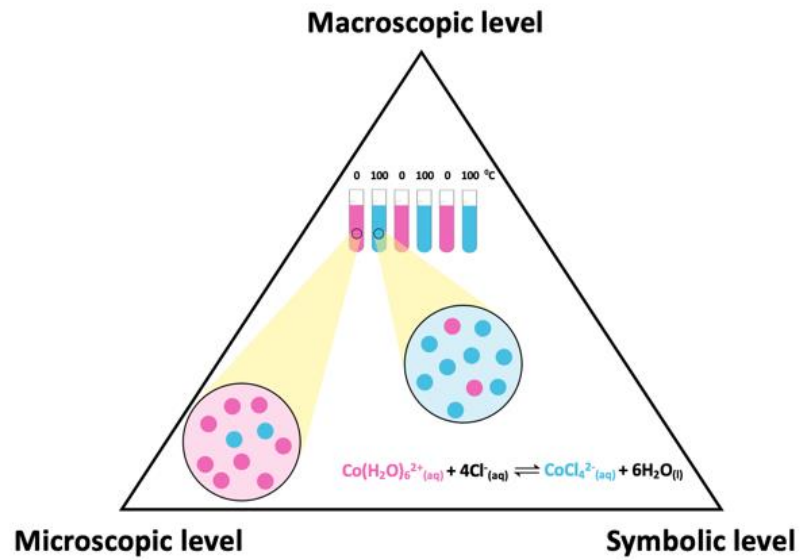

Figure 1: The mental model connected with the three levels of the representation of the reversible reaction.

However, explanations of three levels of representation are connected, as they explain the same matter on different levels. Therefore, to help students understand that the concepts are different, teachers should let students comprehend the three levels of phenomena simultaneously, without separating 
the explanation (Akaygun \& Jones, 2014; Sanchez, 2018). Thus, if the students can visualize the explanation of chemical phenomena by connecting three levels, like the exemplified chemists, it is clear that they will have MMs of reversible reactions similar to the scientific models.

Argumentation within model-based learning (AMBL)

MBL (Harrison \& Treagust, 2000; Khan, 2011; Coll \& Lajium, 2011; Markauskaite et al., 2020) is an instructional method that can develop students' MMs so they are consistent with scientific models (Khan, 2011; Barak \& Hussein-Farraj, 2013; Markauskaite et al., 2020). This begins with the students creating MMs to examine existing knowledge before experimenting to evaluate congruence with the models constituted under empirical evidence. If the created model cannot explain phenomena, the students need to improve or modify the model before implementation to explain new phenomena and to broaden the model (Buckley et al., 2004). This view of MBL is strongly rooted in a social constructivist framework (Scott, Asoko, \& Leach, 2007).

Model-based learning is not only a step-by-step teaching approach; it is also about the sense-making process of natural phenomena through modelling. In the modelling process, argumentation should occur (Berland \& Reiser, 2009; Passmore \& Svoboda, 2012; Evagorou, Nicolaou \& Lymbouridou, 2020) . Argumentation is a dialogic process that involves providing, supporting, challenging, and refining claims using criteria valued in science (Kulatunga, Moog, \& Lewis, 2013; Sampson \& Clark, 2009). Scientific argumentation encourages students to create arguments to explain natural phenomena based on reasoning (Juntunen \& Aksela, 2014). For example, students try to seek empirical evidence to confirm or disprove their claims; thus, argumentation plays an essential role in helping to generate reasonable explanations, models, and theories (Siegel, 1995; Erduran \& Jimenez-Aleixandre, 2012). Similarly, scientists use evidence for claims in creating arguments based on scientific reasons to show relationships between the claims and evidence (Toulmin, 1958). Nevertheless, Sampson and Clark (2009) examined the relationship between co-working and scientific argumentation and found that, to attain better scientific knowledge and understanding, students should jointly construct an argument within the learning exchange. Most of the argumentation that occurs in small groups is coconstructed, suggesting that students work cooperatively in this group setting (Kulatunga, Moog, \& Lewis, 2013)

The researchers assume that engaging students with argumentation in modelbased learning encourages them to enter into ways of thinking, acting, and speaking like scientists. Mendonça and Justi (2013) established relationships between argumentation and modelling in the use of two modelling-based teaching sequences (on ionic bonding and intermolecular interactions). They found that argumentative situations occurred in all stages of model-based learning. Argumentative situations were relevant to students' sense making, articulation and persuasiveness in modelling process. Students should have opportunities to choose and justify their models; propose intermediate models; communicate them to their peers; plan and investigate in order to collect data to 
evaluate their proposals; criticise their models and those of their peers; and modify models according to some criteria or from the commitment to some evidence (Bottcher \& Meisert, 2010; Passmore \& Svoboda, 2011)

According to Mendonca and Justi (2013), the argumentation process should not only emphasize model evaluation but include every step of modelling to make the models to be more complete. Therefore, our study adds an argumentation process to every step of MBL to make the MMs of students more similar to the scientific models. This instructional strategy is referred to as Argumentation within Model-based learning (AMBL). Students should be encouraged to develop more MMs - models that show greater consensus - through modelling and argumentation in their community. They should have a chance to express their own MMs, and to evaluate, justify, and revise their models based on evidence.

\section{Research methodology}

In this study, a qualitative research approach based on an interpretive paradigm (Patton, 2002) was used to build an understanding of how students developed mental models on chemical equilibrium. The context of the study, data collection and analysis are described as follows;

\subsection{Context of the study}

The participants included 29 grade 11 students (nine male students and 20 female students) at a public school in Thailand. All participants have studied at high school level since grade 10. The particular school was chosen for its convenience and proximity; the first author had worked there as a teacher and these students were taught by the first author. These factors allowed us to understand profoundly the degree to which each student developed MMs. In order to teach chemical equilibrium, AMBL was developed based on the literature reviews of MBL and argumentation and consisted of three key features:

Creating knowledge through the modelling process. The students used their existing knowledge/experience to create MMs about the phenomena under study. Since the MMs of students mostly differ from the scientific models, teachers should give students the opportunity to fully express their MMs through drawing, explaining, discussing, and role playing.

Jointly creating knowledge in promoting students to improve/modify their models. Transactions between teachers and students, or students and students, lead to the creation of models that are closer to the scientific models. For example, if the created model cannot explain the phenomena, teachers may facilitate in asking questions to motivate discussion and debate between the teachers and students, or among the students themselves, for more complete model improvement.

Discussion based on empirical evidence for evaluating consistency within the created models. The students should gather empirical data as evidence for examining the consistency of the created models. They should also attempt to explain with empirical data to confirm that the claims or created models are correct, or provide an empirical, evidence-based explanation to explain how the newly created models are better than the old ones. 


\subsection{Data collection and analysis}

To address the two research questions, we gathered and analysed the data using the following tools. The first research question involved what the chemical equilibrium MM of an $11^{\text {th }}$-grade student was like during AMBL. Data were gathered with an MM survey containing mainly open-ended questions for the students to draw pictures and describe their models with detailed reasons (Vosniadou et al., 2004). It was divided into 23 sub-items covering chemical equilibrium content within five main topics, including reversible reaction, equilibrium in chemical reactions, the equilibrium constant, factors affecting equilibrium, and Le Chatelier's principle. The MM survey was developed according to various research (e.g. Srichiangha, 2014; Vosniadou et al., 2004) and then validated by panels of experts. The researchers analysed questions per item by reading all students' answers thoroughly, including the aspects of alternatives, drawn pictures, and the reasons used for explanation and interpretation. After that, following Chi and Roscoe (2002), the answers were used to group the MMs of the students into six groups: correct mental model (CMM); incomplete correct mental model (ICMM); complete faulty mental model (CFMM); faulty mental model (FMM); idiosyncratic mental model (IMM); and no response (NR).

The second question concerned how AMBL developed the MMs of chemical

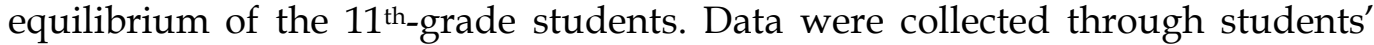
reflective journals, in which they wrote what they learned and expressed their feelings and opinions about the lesson and learning activities in each period. We determined the scope as three main issues: what the students did that day, what they learned, and whether they liked the lesson. Furthermore, a post-teaching log was recorded by the first author. The researchers applied the qualitative data collected for data analysis using the inductive process (Cohen, Manion \& Morrison, 2000). The researchers used the data to interpret and identify shared features of concrete data and to make an abstract conclusion to be synthesized as a theme. Additionally, all data from the interpretation and analysis were examined for validity by two experts and critics for triangulation, who provided suggestions from the data analysis.

\section{Findings}

Students' mental models and ways of enhancing their mental models were presented as follows:

\subsection{The students' MMs}

According to the data collection, when comparing results before and after the AMBL on chemical equilibrium, we identified the development of the 11th-grade students' MMs as follows: After learning, most students had correct mental models (CMM) of the equilibrium state in chemical reactions (52\%), followed by reversible chemical reactions $(31 \%)$. In comparison, with only the instruction provided prior to learning, the students had flawed mental models (FMM) in every aspect, as shown in Table 1. 
Table 1: Number and percentage of the students with chemical equilibrium MMs before and after the Argumentation within AMBL)

\begin{tabular}{|c|c|c|c|c|c|c|c|c|c|c|c|c|}
\hline \multirow{3}{*}{ Issues } & \multicolumn{12}{|c|}{ Number of students [person (percent)] } \\
\hline & \multicolumn{2}{|c|}{ CMM } & \multicolumn{2}{|c|}{ ICMM } & \multicolumn{2}{|c|}{ CFMM } & \multicolumn{2}{|c|}{ FMM } & \multicolumn{2}{|c|}{ IMM } & \multicolumn{2}{|c|}{ NR } \\
\hline & B & A & B & A & B & A & B & A & B & A & B & A \\
\hline $\begin{array}{l}\text { Reversible } \\
\text { reaction }\end{array}$ & $\begin{array}{c}0 \\
(0)\end{array}$ & $\begin{array}{c}9 \\
(31)\end{array}$ & $\begin{array}{c}9 \\
(3)\end{array}$ & $\begin{array}{c}10 \\
(34)\end{array}$ & $\begin{array}{c}5 \\
(19)\end{array}$ & $\begin{array}{c}3 \\
(10) \\
\end{array}$ & $\begin{array}{c}13 \\
(48) \\
\end{array}$ & $\begin{array}{c}5 \\
(17)\end{array}$ & $\begin{array}{c}0 \\
(0) \\
\end{array}$ & $\begin{array}{c}2 \\
(7)\end{array}$ & $\begin{array}{c}0 \\
(0)\end{array}$ & $\begin{array}{c}0 \\
(0)\end{array}$ \\
\hline $\begin{array}{l}\text { Equilibrium in the } \\
\text { chemical reaction }\end{array}$ & $\begin{array}{c}0 \\
(0) \\
\end{array}$ & $\begin{array}{c}15 \\
(52) \\
\end{array}$ & $\begin{array}{c}0 \\
(0) \\
\end{array}$ & $\begin{array}{c}0 \\
(0) \\
\end{array}$ & $\begin{array}{c}3 \\
(11)\end{array}$ & $\begin{array}{c}11 \\
(38) \\
\end{array}$ & $\begin{array}{c}21 \\
(78) \\
\end{array}$ & $\begin{array}{c}0 \\
(0) \\
\end{array}$ & $\begin{array}{c}0 \\
(0) \\
\end{array}$ & $\begin{array}{c}2 \\
(7) \\
\end{array}$ & $\begin{array}{c}3 \\
(11)\end{array}$ & $\begin{array}{c}1 \\
(3)\end{array}$ \\
\hline $\begin{array}{l}\text { Factors affecting } \\
\text { equilibrium }\end{array}$ & $\begin{array}{c}0 \\
(0) \\
\end{array}$ & $\begin{array}{c}5 \\
(17) \\
\end{array}$ & $\begin{array}{c}0 \\
(0) \\
\end{array}$ & $\begin{array}{c}12 \\
(41) \\
\end{array}$ & $\begin{array}{c}3 \\
(11) \\
\end{array}$ & $\begin{array}{c}3 \\
(10) \\
\end{array}$ & $\begin{array}{c}17 \\
(63) \\
\end{array}$ & $\begin{array}{c}9 \\
(31) \\
\end{array}$ & $\begin{array}{c}0 \\
(0) \\
\end{array}$ & $\begin{array}{c}0 \\
(0) \\
\end{array}$ & $\begin{array}{c}7 \\
(26) \\
\end{array}$ & $\begin{array}{c}0 \\
(0) \\
\end{array}$ \\
\hline $\begin{array}{l}\text { Equilibrium } \\
\text { constant }\end{array}$ & $\begin{array}{c}0 \\
(0) \\
\end{array}$ & $\begin{array}{c}5 \\
(17)\end{array}$ & $\begin{array}{c}1 \\
(4)\end{array}$ & $\begin{array}{c}13 \\
(45)\end{array}$ & $\begin{array}{c}3 \\
(11)\end{array}$ & $\begin{array}{c}6 \\
(21) \\
\end{array}$ & $\begin{array}{c}15 \\
(56)\end{array}$ & $\begin{array}{c}1 \\
(3)\end{array}$ & $\begin{array}{c}0 \\
(0) \\
\end{array}$ & $\begin{array}{c}2 \\
(7) \\
\end{array}$ & $\begin{array}{c}8 \\
(30)\end{array}$ & $\begin{array}{c}2 \\
(7) \\
\end{array}$ \\
\hline $\begin{array}{l}\text { Le Chatelier's } \\
\text { principle }\end{array}$ & $\begin{array}{c}0 \\
(0)\end{array}$ & $\begin{array}{c}0 \\
(0)\end{array}$ & $\begin{array}{c}0 \\
(0) \\
\end{array}$ & $\begin{array}{c}4 \\
(14)\end{array}$ & $\begin{array}{c}1 \\
(4)\end{array}$ & $\begin{array}{c}1 \\
(3)\end{array}$ & $\begin{array}{c}21 \\
(78)\end{array}$ & $\begin{array}{c}23 \\
(79) \\
\end{array}$ & $\begin{array}{c}0 \\
(0) \\
\end{array}$ & $\begin{array}{c}0 \\
(0)\end{array}$ & $\begin{array}{c}5 \\
(19)\end{array}$ & $\begin{array}{c}1 \\
(3)\end{array}$ \\
\hline
\end{tabular}

Note: B- Before, A- After, CMM: correct mental model; ICMM: incomplete correct mental model; CFMM: complete faulty mental model; FMM: faulty mental model; IMM: idiosyncratic mental model; NR: no response.

\section{Reversible chemical reaction}

For this topic, the teacher asked the students to select different scientific models in a preparation process of ammonia gas as a raw material for producing fertilizer. The students needed to select the best possible model when opening a valve for $\mathrm{N}_{2}$ and $\mathrm{H}_{2}$ to be mixed to become $\mathrm{NH}_{3}$ (in a third tank), as shown in Figure 2.

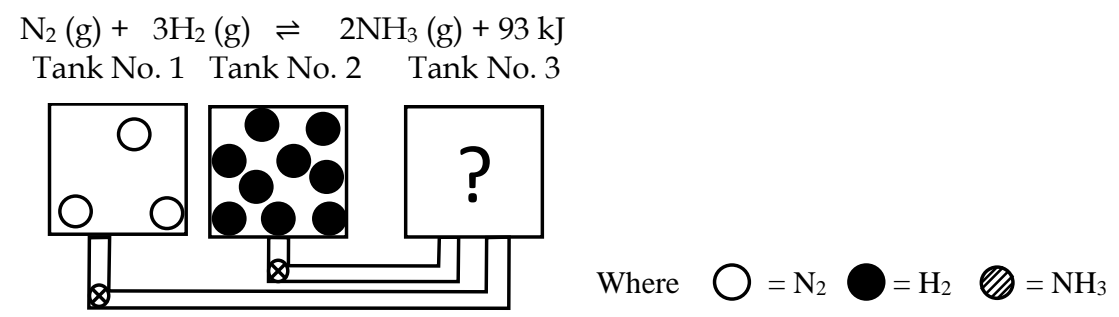

Figure 2: Illustration of the question in issue of the reversible chemical reaction, equilibrium in the chemical reaction, and factors affecting chemical equilibrium.

Before learning, it was found that the students mostly had FMM (48\%). When analysed, the only answer was that the substrates reacted entirely to become products. That is, $\mathrm{N}_{2}$ reacted with $\mathrm{H}_{2}$ entirely to become $\mathrm{NH}_{3}$. This indicated that the students exercised the concept of complete reaction, and most students in this group answered 'because a molecule of $\mathrm{N}_{2}$ is combined with 3 molecules of $\mathrm{H}_{2}$ to be a molecule of $\mathrm{NH}_{3}$. Therefore, 3 molecules of $\mathrm{N}_{2}$ and 9 molecules of $\mathrm{H}_{2}$ can be combined to be 3 molecules of $\mathrm{NH}_{3},{ }^{\prime}$ as shown in Figure 3 a.

After the lesson, the students had increased their CMM by 31\%, showing that they experienced development in their MMs. When analysing the students' answers, the researchers found two patterns. In the first pattern, students selected the first model because of a molecule of $\mathrm{N}_{2}$ reacting with three molecules of $\mathrm{H}_{2}$ to become two molecules of $\mathrm{NH}_{3}$. The substance particles would not react entirely because the students misinterpreted meanings from the chemical equation with reversible marks. Most students interpreted meanings from the symbols representing the 
reversible reaction. That is, the reversible reaction $(\rightleftharpoons)$ was connected with the particulate model. The students explained 'because a molecule of $\mathrm{N}_{2}$ is combined with 3 molecules of $\mathrm{H}_{2}$ to become 2 molecules of $\mathrm{NH}_{3}$, as it was a reversible reaction without complete change or reaction', as shown in Figure 3b. In the second pattern, students selected $\mathrm{Y}$ model because a molecule of $\mathrm{N}_{2}$ reacted with three molecules of $\mathrm{H}_{2}$ to become two molecules of $\mathrm{NH}_{3}$; the substance particle did not react completely because the students could visualize it at the microscopic level.

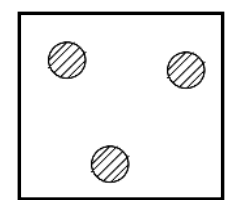

(a)

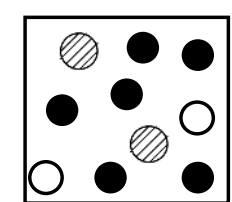

(b)

Figure 3: The model selected by the students (the third tank) when opening a valve for $\mathrm{N}_{2}$ and $\mathrm{H}_{2}$ to be combined.

Equilibrium in the chemical reaction

In this topic, the teacher used a situation linked with the first point and added a question about which, when entering the equilibrium state, substance particles in the third tank would be drawn and described. Before learning, most students had FMM (78\%). When analysing the students' answer patterns, we found two patterns. In pattern one, the system entered an equilibrium state when the substrates reacted entirely to become products. In this pattern, the students understood that when substrates do not entirely react, the system does not enter the equilibrium state. However, if the substrates completely react to become products, the system will reach equilibrium. A student in this group explained that 'when 3 molecules of $\mathrm{N}_{2}$ are combined with 9 molecules of $\mathrm{H}_{2}$, the product will be 3 molecules of $\mathrm{NH}_{3}$ ', as shown in Figure 4 a. In the second pattern, the system will be in equilibrium when the quantity of each kind of substance particle is equal. This pattern of answers indicated that the students comprehended that the system was in equilibrium, as in the expression 'same or equal.' Accordingly, the students visualized particles with the same quantity; the system would thus be in equilibrium when the quantity of particles of every substance was equal. A student explained that 'there are equal numbers of particles in the equilibrium', as shown in Figure 4b. After learning, the students developed more CMM (52\%). When analysing the answers, the teacher found only one pattern, as most students understood that when the system is in equilibrium, nitrogen reacts with hydrogen to become ammonia gas, and it disintegrates to become nitrogen and hydrogen because the rate of forward reaction is equal to the reverse reaction. One student answered, 'There were $3 \mathrm{~N}_{2}$ and $9 \mathrm{H}_{2} 9$ with a ratio of 1:3, and they would be combined to become $2 \mathrm{NH}_{3}$, but there were $1 \mathrm{~N}_{2}$ and $3 \mathrm{H}_{2}$ left because the equilibrium is reversible', as shown in Figure 4c. Additionally, the students had complete faulty mental models (CFMM), as they perceived that when the system entered dynamic equilibrium, the substrates reacted to become the products at the same ratio of the chemical equation, and the reaction was not complete. Some students in the group explained that the 'forward reaction from substrates became 
the products to decrease 1 nitrogen and 3 hydrogens to increase 2 ammonias', as shown in Figure $4 \mathrm{~d}$.

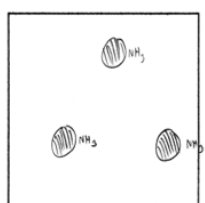

(a)

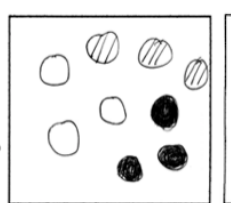

(b)

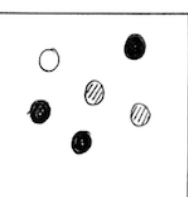

(c)

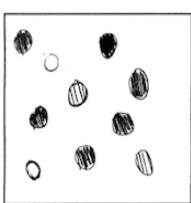

(d)

Figure 4: The drawings of students showing gas particles in the third tank when the system is in equilibrium.

\section{Factors affecting equilibrium}

For this point, the teacher used connected situations from the issue of equilibrium in the chemical reaction but added the condition that the substance particles in the third tank must be drawn when interrupted by increasing pressure. Before learning, most students had FMM (63\%), while some students provided no response (NR). When analysed, there were three answer patterns. In the first, increasing pressure made the gas particles closer because of the decrease in space or volume of the gas particles. In the second answer pattern, increasing pressure caused more ammonia because of increased substrate reaction. Finally, in the third pattern, decreasing pressure increased the volume of the gas particles, leading to more products. Some examples of the students' responses: 'when increasing pressure in a gas cylinder, nitrogen and hydrogen will be more disintegrated, leading to the increase of reaction of both gases, and more ammonia is produced' (Figure 5a), and 'when increasing pressure, the ammonia particles will be closely arranged, showing more exothermic process and increasing ammonia' (Figure 5b). After learning, almost half of the students had incomplete correct mental models (ICMM; 41\%). When analysing the answer patterns of the students, we found only one pattern: increasing pressure led to more ammonia or more forward reaction because of the substrate reaction, but the reaction was not complete. An example of a student's answer is: 'when reducing pressure and volume, the substances would collide more, resulting in more reactions and increasing ammonia, but it is still reversible' (Figure 5c). Meanwhile, some students had increased CMM (17\%), and there were two answer patterns. In the first pattern of answers, increasing pressure led to the production of more ammonia due to particles of the substrates being more than products; the system balanced it by making the substrate's particles react to generate more ammonia. This indicated that the students could explain changes at the microscopic level. Some students who followed this pattern explained that 'when increasing pressure, the volume is decreased, and the substrates turn to be more products because of more substrates. As a result, when reducing the volume of the substances, the quantity must be decreased' (Figure $5 \mathrm{~d}$ ). In the second pattern, increasing pressure resulted in more ammonia because the volume reduction affected the coefficient of high Mol moving to low Mol. This indicated that the students' explanations relied on the relationship of the reaction proportion according to the relative quantity. An example of a student's answer included that, when increasing pressure, the volume and space would be decreased. As a 
result, the particles collided more, leading to an increasing amount of ammonia (volume decreased from high Mol to low Mol).

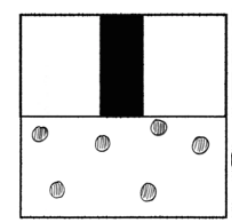

(a)

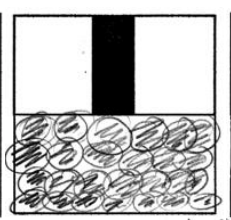

(b)

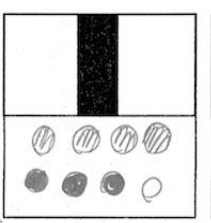

(c)

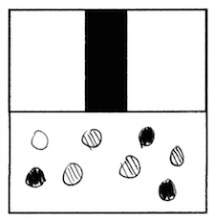

(d)

Figure 5: Student drawing demonstrating gas particles in the third tank under increasing pressure.

\section{Equilibrium constant}

Regarding this topic, the teacher asked the students to draw substance particles from the equilibrium constant of nitrogen monoxide generation $\left(\mathrm{N}_{2}+\mathrm{O}_{2} \rightleftharpoons 2 \mathrm{NO}\right)$. The students needed to understand that the equilibrium constant could only happen when the system was in equilibrium. Before learning, it was found that most students had FMM (56\%). After learning, almost half of the students had ICMM. Some students had CMM and IFMM. When analysing the students' answer patterns, the teacher found two patterns. In the first answer pattern, air consisted of $\mathrm{N}_{2}, \mathrm{O}_{2}$, and $\mathrm{NO}$ equally because the substrates reacted to become the products. For example, some students explained that 'when $\mathrm{N}_{2}$ and $\mathrm{O}_{2}$ in the air are combined, it become NO' (Figure 6a). In the second pattern, only NO was found in the air because $\mathrm{N}_{2}$ reacted with $\mathrm{O}_{2}$ completely due to the complete reaction. The students explained that in the equilibrium state, $\mathrm{N}_{2}$ and $\mathrm{O}_{2}$ are combined entirely to become NO' (Figure 6b). After learning, almost half of the students had ICMM (45\%). When analysing the answer patterns of the students, the teacher found only the pattern that $\mathrm{N}_{2}$ reacted with $\mathrm{O}_{2}$ to become $\mathrm{NO}$ at a ratio of $1: 1: 2$, in accordance with the same proportion of the equation, because the students considered the reversible chemical equation and interpreted it at the microscopic level. One student explained: ' $\mathrm{N}_{2}+\mathrm{O}_{2} \rightleftharpoons 2 \mathrm{NO}$ at a ratio of $1: 1: 2$, thus, there are $3 \mathrm{~N}_{2}, 3 \mathrm{O}_{2}$, and $6 \mathrm{NO}^{\prime}$ (Figure 6c). In the meantime, the number of students with CMM increased by $17 \%$. However, when considering the answer pattern of the students, the teacher found the same pattern as the ICMM group. However, this group additionally explained that the substrates are left to generate a reversible reaction.' Therefore, they were categorized in the CMM group. One student in this group answered that ' $\mathrm{N}_{2}+\mathrm{O}_{2} \rightleftharpoons 2 \mathrm{NO}: \mathrm{N}_{2}$ reacts with $\mathrm{O}_{2}$ to become the new product, which is NO, and it is reversible' (Figure 6d). 


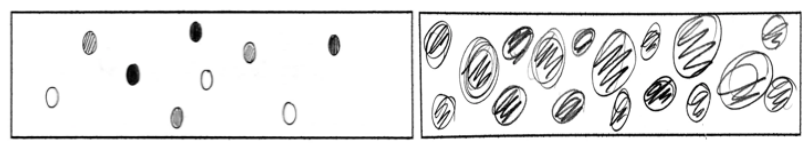

(a) (b)

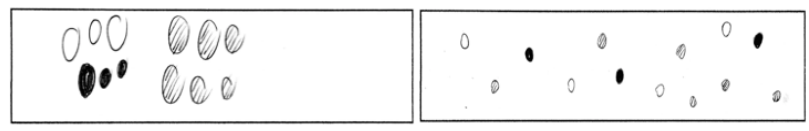

(c)

where $\mathrm{O}=\mathrm{N}_{2} .=\mathrm{H}_{2} \oslash=\mathrm{NO}$

(d)

Figure 6: Pictures of the students showing gas particles in the air.

\section{Le Chatelier's principle}

The teacher presented a hypothetical situation about hiking Mt. Everest, where a person in such a high place would have a headache and nausea because oxygen would not sufficiently nourish the body tissues; these symptoms constitute hypoxia. The equation was as follows: $\mathrm{Hb}+\mathrm{O}_{2} \rightleftharpoons \mathrm{HbO}_{2}$. The teacher asked the students to draw the substance particles in a case where the Mt. Everest hiker had a blood test to identify hypoxia, with a 1-hour X-ray. Before learning, the students had FMM, which was not different from post learning, where the students still had FMM $(80 \%)$. When analysing the answer patterns of the students, we found three patterns. In the first pattern, the students did not show the particles of $\mathrm{HbO}_{2}$ because the amount of $\mathrm{O}_{2}$ was insufficient; thus, $\mathrm{HbO}_{2}$ was not found to nourish the body. In the second answer pattern, the students did not show particles of $\mathrm{O}_{2}$ due to an inadequate amount of $\mathrm{O}_{2}$; thus, the particles were not found in the body. Finally, in pattern three, the students supposed that when time passed, the forward reaction would occur and finally become complete (Figure 7a). After learning, the answer pattern was the same as the third pattern, which accounted for $50 \%$ of the students in the FFM group. The answering pattern differed from before learning in that the students thought that dynamic equilibrium had occurred and that the particles had not increased, leading to hypoxia. The students understood that the dynamic equilibrium resulted in limited constant particles, and they thought that the $\mathrm{O}_{2}$ particles were few, bringing about few $\mathrm{HbO}_{2}$ molecules. The students answered that ${ }^{\prime} \mathrm{HbO}_{2}$ may be the same because $\mathrm{O}_{2}$ in the atmosphere is low, and when $\mathrm{HbO}_{2}$ is low the oxygen cannot nourish the body, leading to hypoxia' (Figure 7b). However, after learning, some students had $\operatorname{ICMM}(14 \%)$, compared with zero students who had CMM before learning. When analysing the answer patterns, we found that there was only one pattern, which was that hypoxia decreased the concentration of oxygen as the substrate. Therefore, the system would adapt, leading to fewer particles of the products, thus increasing the substrate's particles. This indicated that the students used the main concept of Le Chatelier's principle regarding the factors of concentration to explain substance adaptation for the system to be in equilibrium. A student in this group answered that 'in the $60^{\text {th }}$ minute, the particles of $\mathrm{HbO}_{2}$ are low, while the particles of $\mathrm{Hb}$ are high and the particles of $\mathrm{O}_{2}$ are low, leading to low $\mathrm{HbO}_{2}$ " (Figure 7c). 


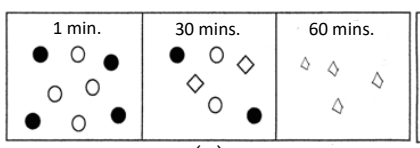

(a)

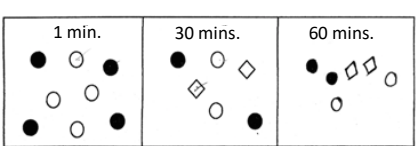

(b)

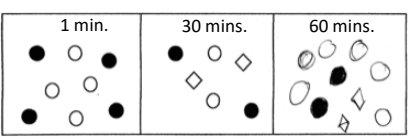

(c)

where $\mathrm{O}=\mathrm{Hb} \quad \bigcirc=\mathrm{O}_{2} \diamond=\mathrm{HbO}_{2}$

Figure 7: Drawing of the students showing substance particles when a hiker has hypoxia.

\subsection{In what ways did students develop MMs in chemical equilibrium?}

Creating different mental models led to conviction in jointly developing MMs in accordance with the scientific models.

To realize their MMs, the students needed to evaluate the created models by presenting to other groups. Different existing experiences compelled the students to create distinct models, leading to the conviction process. A technique used was that the group creating an FMM would give their presentation first, and the group creating the model consistent with the scientific models would present later. As a result, the group with the FMM would be convinced to adjust their models. Such a technique is highly effective because the students in the classroom would realize their errors and correct the models. However, the co-point of both models was the alternative model used to explain the same phenomena, with a different agreement with the scientific models. The students would perceive the development of the models from the conviction process for model modification. An advantage of the model development was that the students selected a developed model to explain the phenomena. On the other hand, the model before development would not be chosen by the students to explain the phenomena because it had not been covered in the lesson.

The students constructed the models at the particulate level to explain the phenomena of reversible reactions between cobalt (II) sulphate and hydrochloric acid when cooled and heated. The teacher asked the students to present their created models and found that the students created different models. The presentation started with the group with faulty models (which the teacher identified by surveying the students while they created their models). After that, the group had models in agreement with the scientific models. An example of a conversation between the teacher and students follows:

Teacher: When heating the solution, what colour do you notice?

Student A: It's blue, so I moulded it with blue colour.

Teacher: If it is cooled, what is it like?

Student A: The solution will turn from blue to pink, so our group moulded it with pink plasticine. (This student is representative of the faulty model.)

Teacher: Is there any group different from this one?

Student B: My group. We think that it will not be only blue or pink, as there must be remainders for the reversible reaction. (This is the conviction process to link their groups' models.)

(This student is representative of the correct model.)

Teacher: Do you agree with this group?

All Students in Class: Yes.

Teacher: If I let you revise the model, what will it look like?

Student C: The substrates will remain. 
As the above conversation illustrates, the teacher provided the group with the faulty models with the opportunity to present first, by asking the question, 'Is there any group different from this group?' This was to give an opportunity to the group with the correct model an opportunity to present and convince their peers that their group created the correct model. Some students understood that the reversible reaction should have a complete reaction before a reverse reaction. Thus, the students created the models with no remaining substrate particles (Figure 8a). Meanwhile, as another group argued that the reversible reaction did not react entirely, the students created models with substrate particles remaining (Figure $8 \mathrm{~b}$ ). The reasoning of the group with the correct models was more reliable than the first group, and they could convince their friends. Additionally, the teacher asked the questions necessary to make the modification more effective, such as 'Do you agree with this group?' and 'If I let you revise the model, what will it look like?' When analysing the students' diaries, the teacher found agreement. That is, the conviction process contributed to the students' model development. Examples of a student's diary included: 'I learned about substances that are reversible because they do not completely change and there are particles left to be reversible', and 'I know that the complete substance is not reversible because it is complete. That is, no other substances disturb. If there are other substances, it will be reversible because of the presence of other matter'.

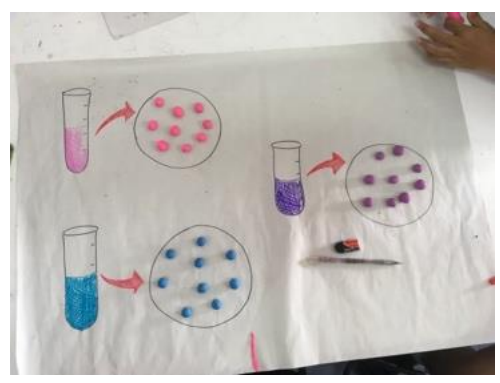

(a)

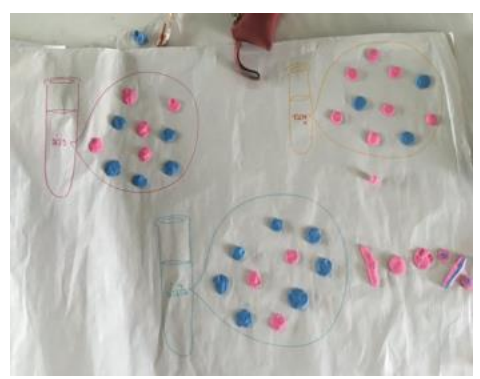

(b)

Figure 8: The mental models of the group with (a) a faulty model and (b) a model similar to the scientific models in explaining the colour changes of the solution from the experiment.

\section{Analogical method promoting modelling at the microscopic level}

Analogy is a necessary technique for the creation of MMs, especially microscopic models. The analogy helped the students to visualize the invisible content, such as the dynamic equilibrium phenomena, in which the forward reaction is equal to the reversible reaction at any time. However, since the students could not see it, to represent the concept the teacher used the analogy of alternating water fetching under the condition that the containers should have the same volume. The teacher asked the students to construct their MMs on the microscopic level through role playing. When fetching water for a moment, the students noticed the constant equivalent volume. The analogy promoted the students' vision of dynamic equilibrium as the rate of forward change equal to reversible change. An example of a conversation between the teacher and students about the analogy of water fetching follows: 
Teacher: Which substance has more initial volume? (The teacher fetched water with his hands. At first, since there was no volume of the product, he fetched the air.)

Student D: The substrates are more than products.

Teacher: What happens when time passes?

Student E: The substrates are equal to the products.

Teacher: When do the substrates equate to the products?

Student F: When the water in both beakers is equal.

Teacher: If time passes for one day, ten days, or 100 years, what do you think the substance quantity will be?

Student F: It will be the same.

Teacher: What do you think the beakers look like in the chemical reaction?

Student F: Rate of forward reaction and reverse reaction.

Asking the students to explain the phenomenon of chemical equilibrium by linking the three levels of representation through the modelling process to make MMs consistent with the scientific models.

The teacher emphasized his instruction to the students to explain the phenomenon at three levels through the creation of the MMs. For instance, the students were asked to experiment and observe the colour change before creating a model to explain the substance's behaviour at the particulate level and to determine the chemical symbols to link with the explanation at both levels. This pattern of teaching would be obvious in the first and fourth learning plans, as exemplified in the fourth learning plan.

At the macroscopic level, the teacher required the students to perform an experiment or activity to explain the factors of concentration affecting the equilibrium, observing whether the substance was more or less concentrated. Questions asked after the experiment required the students to give reasons for the colour change, such as the colour changing when adding $\mathrm{Fe}\left(\mathrm{NO}_{3}\right)_{3}$ to the solution, the cause, the observation, and the exemplification of the students' answers in some groups. For example, when adding $\mathrm{Fe}\left(\mathrm{NO}_{3}\right)_{3}$, the solution's colour was darker because the substrates reacted increasingly to generate more products. Some noticed that the substance in the test tube had a darker red colour. To obtain more concrete data and to demonstrate the symbolic models, the teacher then asked the students to use a graph drawing to explain the representation, at the symbolic level, between the concentration change over a period of time, as depicted in Figure 9a. The conversation between the teacher and the students was as follows:

Teacher: When mixing substrates and the system is in equilibrium, what does the graph look like? Student A: It's parallel (symbolic).

Teacher: When adding $\mathrm{Fe}^{3+}$, do you think the graph is still parallel?

Student A: I don't think so, as we are interrupting the equilibrium (symbolic).

Teacher: What is increased when adding $\mathrm{Fe}^{3+}$ ?

Student A: The concentration of $\mathrm{Fe}^{3+}$ increases.

Teacher: What should the graph look like?

Student A: It rises/becomes higher (symbolic).

Teacher: What is the concentration of $\mathrm{Fe}^{3+}$ when time passes? 
Student A: It decreases, because it will react more with the darker colour of the solution (macro). Teacher: What should the graph look like?

Student A: It descends.

Teacher: What is the concentration of SCN-?

Student A: It decreases only (symbolic).

The teacher attempted to use questions to stimulate the students to link to the representation. For example, what does the graph look like when substrates are mixed and the system achieves equilibrium? Or what is increased when adding $\mathrm{Fe}^{3+}$ ? This indicated that the teacher's questions contributed to the students' understanding in creating the symbolic models to make the data more concrete. After that, the intent was to link the microscopic representation to the symbolic level. The teacher asked the students to explain the substance's behaviour on the microscopic level using coloured papers cut into circles to represent the substance's particles. The students were asked to use the papers for the particles' representation by demonstrating the particles in four periods, according to the students' work: the beginning, when achieving equilibrium, when adding $\mathrm{Fe}^{3+}$, and when returning to equilibrium, as shown in Figure 9b. When the students created the models at the particulate level, the teacher needed to link the three levels of representation by questioning the students, as seen below:

Teacher: What does the graph look like when mixing both substances?

Student A: Parallel (symbolic).

Teacher: What is the substance particle's ratio?

Student A: The particles are at a ratio of 1:1:1 (micro).

Teacher: What do the particles look like when adding $\mathrm{Fe}^{3+}$ ?

Student A: When adding $\mathrm{Fe}^{3+}$, there are 6 yellow particles, 3 colourless particles, and 3 red particles. When the system has just reached equilibrium, the yellow particles react with the colourless particles to become red particles. There are 4 yellow particles, 1 colourless particle, and 5 red particles left.

Teacher: How is it consistent with the graph?

Student A: When adding $\mathrm{Fe}^{3+}$, the concentration of $\mathrm{Fe}^{3+}$ increases, and the graph rises (symbolic) to the new equilibrium. Then, the graph descends (symbolic) because of forward reaction as the solution's colour gets darker (macro). Meanwhile, the concentration of SCN- decreases (symbolic), and the concentration of $[\mathrm{FeSCN}]^{2+}$ is higher (symbolic).

Teacher: Is it consistent with the representation at the particulate level?

Student A: Yes, it is.

As the conversation above, having the students understand abstract matters can be concretized in two ways. By drawing a graph, the students could interpret the data of the representation on the macroscopic level in a concrete manner, but the particulate-level modelling could help them explain the behaviours of the substances, such as which substance reacted with which substance, the remainder, and the state of the particles upon equilibrium. 


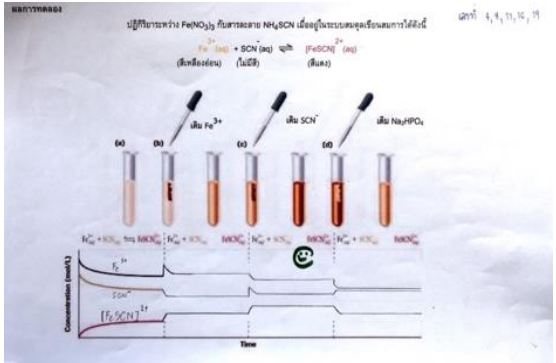

(a)

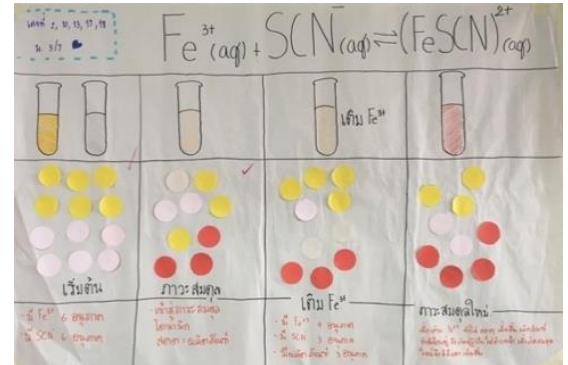

(b)

Figure 9: Symbolic modelling (graph) and concentration changes over a period of time, and linking the representation at the macroscopic and microscopic levels.

\section{Conclusion, Discussion, and Implications}

The research findings provide knowledge about MBL, especially as it concerns increasing and emphasizing argumentation to enhance students' mental models (MMs). AMBL could develop the MMs of the students to align to scientific models (Khan, 2011; Barak \& Hussein-Farraj, 2013; Potisen \& Faikhamta, 2017; Markauskaite et al., 2020). Through the modelling process, the students could create their MMs to understand the representation of chemical equilibrium on three levels. Additionally, the students could generate arguments for developing their MMs to become similar to the scientific models.

When comparing the results before and after AMBL, most students had CMM for the aspect of equilibrium in the chemical reaction and reversible reaction. Compared to before learning, the students had FMM for every point. Reviewing the reversible reaction before learning, since the students understood that the particles of the substrates reacted entirely and became the products, almost half of them had FMM. A cause of this misaligned understanding was that the students could not differentiate between the complete reaction and the reversible reaction. Consistent with the findings of Van Driel and Gräber (2002), introducing a lesson with chemical reactions helped the students understand that the reaction happened in the same direction. That is, the substrates reacted and produced the products completely, and the products could be reversed to become the substrates. After learning, the students had CMM (31\%), explaining that the reversible reaction occurred when the particles of the substrates reacted to become the particles of the product. Their reasons explaining that substrate particles did not completely react, are (1) the interpretation of the symbols representing the reversible reaction, which was the reversible chemical equation $(\rightleftharpoons)$, connected with the models at the particulate level (Srichiangha, 2014), and (2) the comparison between the complete reaction model and the reversible reaction model. The students reflected that they employed the created models as scientific knowledge to explain the chemical phenomena.

The argumentative situation can be applied to a discussion of models during model-based learning (Mendonca \& Justi, 2013). While argumentation occurred in all stages of model-based learning, the teacher played a vital role in fostering discussion. The researchers support Clement and Rea-Ramirez (2008), who stressed the importance of teachers asking questions during model-based 
learning. The teacher should ask supporting and discrepant questions to encourage students to evaluate, revise, generalise, and use their knowledge. As shown in the teacher-student dialogues, the teacher facilitated the construction of the students' models, asking questions about the models, investigating the empirical evidence, and providing clear justification for evaluating and modifying their models.

One of the key features of AMBL in supporting the students' explanations was that the students explained the phenomenon of chemical equilibrium through the modelling process by linking the representation on three levels. As a result, the students had MMs in accordance with the scientific models. For example, the students experimented to observe colour changes (macroscopic level), created models to explain the behaviours of the particles (microscopic level), and defined the chemical symbols to link the explanation on both levels. It was clear that the students observed the reversible symbol $(\rightleftharpoons)$ as linked with the reversible representation on the microscopic level. According to the reasoning of the students regarding the second point, the students created the microscopic models to differentiate between the alternative models (the complete reaction models) and the scientific models (the reversible reaction models). When revising their models, the students usually created different models, resulting in a conviction process. However, the effective conviction gave each group a chance to present their models, and the students had learned the alternative and scientific models. Vosniadou (1994) supported the idea that the alternative model was an MM that differed from the scientific models; it was another alternative in explaining the phenomenon. The students may have used the alternative model to compare with the scientific models when describing the phenomena. This aligns with the research study of Faikhamta and Supatchaiyawong (2014), in which the MBL was a learning process where the students could practice thinking scientifically so that they would understand the scientific models as scientific know-how created by scientists to explain natural phenomena.

Based on the research results, the researchers have the following recommendations. First, for instruction with AMBL, teachers should give students a chance to understand the three levels of representation through the modelling process. This can start with an experiment that allows students to observe visible phenomena before explaining the behaviours of the substances at the particulate level. The students can link the macroscopic and microscopic changes to transition abstractness and concreteness, and an analogical technique can help students explain the invisible phenomenon or the particulate model. Second, based on a lesson teaching Le Chatelier's principles, we would like to recommend that instructors may allow students to create models at the microscopic level for the aspects of increasing and decreasing concentrations, which are not separable. However, students may spend a great deal of time creating a microscopic model when just increasing the concentration, and the teacher may have to ask them to link alterations for the two remaining levels, which may also be time consuming. Therefore, it is recommended that animations be used to help explain the phenomenon of de-concentration for the students creating the microscopic model of the concentration increase. This will save time 
and allow the students to achieve MMs consistent with the scientific model. Last, students can use AMBL to address reasons for creating their models, to modify and revise the models, or to reason in support of their claims - all of which require that teachers provide the students with the opportunity to fully give their opinions. Teachers may ask questions such as, 'Does anyone agree/not agree with your friend?' in a case where the students have different opinions, or 'Are your models different from this group's?' in a case where the students create different models. Moreover, 'How do you know?' is a question that stimulates students to find evidence to confirm their reasoning, while 'Do you agree with your friend?' and 'How can you adjust it?' encourage students to practise listening to others' opinions of their reasoning. Therefore, these questions contribute substantially to stimulating students when constructing models or providing explanations for scientific reasoning.

While this study focused on argumentation as a key component embedded in MBL, we did not investigate students' argumentation skills. It would be interesting for further research to investigate and develop students' argumentation skills when using AMBL (Aydeniz \& Dogan, 2016; Juntunen \& Aksela, 2014). Such research might focus on how students develop their argumentation skills and argumentative discourse. To enhance students' argumentation skills, AMBL may also be integrated with animated media and technology to contribute to model presentation (Buckley, 2000; Fretz et al., 2002; Barak \& Hussein-Farraj, 2013; Markauskaite et al., 2020).

Additionally, it is important to investigate how teachers teach MBL in a chemistry context. A chemistry teacher must have pedagogical content knowledge (PCK) to teach specific chemistry concepts, such as chemical equilibrium (Akin \& Uzuntiryaki-Kondakeci, 2017). Teachers are required not only to understand chemistry concepts but must know how to teach argumentation skills in specific chemistry topics to a particular group of students (Bucat, 2014). This kind of study will provide an in-depth understanding of teaching chemistry.

\section{References}

Akaygun, S., \& Jones, L. L. (2014). Words or Pictures: A comparison of written and pictorial explanations of physical and chemical equilibria. International Journal of Science Education, 36(5), 783-807.

Akın, F. N., \& Uzuntiryaki-Kondakci, E. (2018). The nature of the interplay among components of pedagogical content knowledge in reaction rate and chemical equilibrium topics of novice and experienced chemistry teachers. Chemistry Education Research and Practice, 19(1), 80-105.

Aydeniz, M., \& Dogan, A. (2016). Exploring the impact of argumentation on pre-service science teachers' conceptual understanding of chemical equilibrium. Chemistry Education Research and Practice, 17(1), 111-119.

Barak, M., \& Hussein-Farraj, R. (2013). Integrating model-based learning and animations for enhancing students' understanding of proteins structure and function. Research in Science Education, 43(2), 619-636.

Berland, L. K., \& Reiser, B. J. (2009). Making sense of argumentation and explanation. Science education, 93(1), 26-55. 
Bongers, A., Northoff, G., \& Flynn, A. B. (2019). Working with mental models to learn and visualize a new reaction mechanism. Chemistry Education Research and Practice, 20(3), 554-569.

Bottcher, F., \& Meisert, A. (2011). Argumentation in science education: A model-based framework. Science \& education, 20(2), 103-140.

Bucat, R. (2004). Pedagogical content knowledge as a way forward: Applied research in chemistry education. Chemistry Education Research and Practice, 5(3), 215-228.

Buckley, B. C. (2000). Interactive multimedia and model-based learning in biology. International Journal of Science Education, 22(9), 895-935.

Buckley, B. C., Gobert, J. D., Kindfield, A. C., Horwitz, P., Tinker, R. F., Gerlits, B., ..., Willett, J. (2004). Model-based teaching and learning with BioLogica ${ }^{\mathrm{TM}}$ : What do they learn? How do they learn? How do we know? Journal of Science Education and Technology, 13(1), 23-41.

Cascarosa, E., Sánchez-Azqueta, C., Gimeno, C., \& Aldea, C. (2020). Model-based teaching of physics in higher education: a review of educational strategies and cognitive improvements. Journal of Applied Research in Higher Education.

Cheng, M.-F., Wu, T.-Y., \& Lin, S.-F. (2019). Investigating the Relationship Between Views of Scientific Models and Modeling Practice. Research in Science Education, 1-17.

Chi, M. T., \& Roscoe, R. D. (2002). The processes and challenges of conceptual change. In Reconsidering conceptual change: Issues in theory and practice (pp. 3-27): Springer.

Clement, J. J., \& Rea-Ramirez, M. A. (2008). Model based learning and instruction in science. Model based learning and instruction in science, 1-9.

Cohen, L., Manion, L., \& Morrison, K. (2000). Research methods in education. London, UK: Routledge.

Coll, R. K., \& Lajium, D. (2011). Modeling and the future of science learning. In Models and modeling (pp. 3-21): Springer.

Coll R. K., \& Taylor N., (2002). Mental models in chemistry: senior chemistry students' mental models of chemical bonding. Chemistry Education Research and Practice, 3(2), 175-184.

Erduran, S., \& Jiménez-Aleixandre, M. P. (2012). Argumentation in science education research: Perspectives from Europe. In Science Education Research and Practice in Europe (pp. 253-289): Brill Sense.

Evagorou, M., Nicolaou, C., \& Lymbouridou, C. (2020). Modelling and Argumentation with Elementary School Students. Canadian Journal of Science, Mathematics and Technology Education, 1-16.

Faikhamta C., \& Supatchaiyawong P. (2014). Model-Based Learning. Kasetsart Educational Review, 28(2), 1-13.

Faikhamta C. (2016). Issues and Research Trends in Science Education, J. Res. Unit Sci. Technol. Environ. Learning, 7(1), 163-183.

Fretz, E. B., Wu, H.-K., Zhang, B., Davis, E. A., Krajcik, J. S., \& Soloway, E. (2002). An investigation of software scaffolds supporting modeling practices. Research in Science Education, 32(4), 567-589.

Giere, R. N. (2001). A new framework for teaching scientific reasoning. Argumentation, 15(1), 21-33.

Gilbert, J. K. (2005). Visualization: A metacognitive skill in science and science education. In Visualization in science education (pp. 9-27): Springer.

Gilbert, J. K., Boulter, C. J., \& Elmer, R. (2000). Positioning models in science education and in design and technology education. In Developing models in science education(pp. 3-17): Springer. 
Gkitzia, V., Salta, K., \& Tzougraki, C. (2020). Students' competence in translating between different types of chemical representations. Chemistry Education Research and Practice, 21(1), 307-330.

Hackling, M. W., \& Garnett, P. J. (1985). Misconceptions of chemical equilibrium. The European Journal of Science Education, 7(2), 205-214.

Harrison, A. G., \& Treagust, D. F. (1996). Secondary students' mental models of atoms and molecules: Implications for teaching chemistry. Science education, 80(5), 509-534.

Harrison, A. G., \& Treagust, D. F. (2000). A typology of school science models. International Journal of Science Education, 22(9), 1011-1026.

Jiménez-Aleixandre, M. P., \& Erduran, S. (2007). Argumentation in science education: An overview. In Argumentation in science education (pp. 3-27): Springer.

Johnstone, A. H. (1993). The development of chemistry teaching: A changing response to changing demand. Journal of chemical education, 70(9), 701.

Juntunen, M., \& Aksela, M. (2014). Education for sustainable development in chemistrychallenges, possibilities and pedagogical models in Finland and elsewhere. Chemistry Education Research and Practice, 15(4), 488-500.

Justi, R., \& Gilbert, J. (2002). Models and modelling in chemical education. In Chemical education: Towards research-based practice (pp. 47-68): Springer.

Karpudewan, M., Treagust, D. F., Mocerino, M., Won, M., \& Chandrasegaran, A. L. (2015). Investigating high school students' understanding of chemical equilibrium concepts. International Journal of Environmental and Science Education, 10(6), 845863.

Khan, S. (2011). What's missing in model-based teaching. Journal of Science Teacher Education, 22(6), 535-560.

Kousathana, M., \& Tsaparlis, G. (2002). Students' errors in solving numerical chemicalequilibrium problems. Chemistry Education Research and Practice, 3(1), 5-17.

Kulatunga, U., Moog, R. S., \& Lewis, J. E. (2013). Argumentation and participation patterns in general chemistry peer-led sessions. Journal of Research in Science Teaching, 50(10), 1207-1231.

Leach, J., \& Scott, P. (2003). Individual and sociocultural views of learning in science education. Science E education, 12(1), 91-113.

Maia, P. F., \& Justi, R. (2009). Learning of chemical equilibrium through modelling-based teaching. International Journal of Science Education, 31(5), 603-630.

Markauskaite, L., Kelly, N., \& Jacobson, M. J. (2020). Model-based knowing: How do students ground their understanding about climate systems in agent-based computer models? Research in Science Education, 50(1), 53-77.

Mendonça, P. C. C., \& Justi, R. (2013). The relationships between modelling and argumentation from the perspective of the model of modelling diagram. International Journal of Science Education, 35(14), 2407-2434.

Nersessian, N. J. (2010). Creating scientific concepts: MIT press.

Özmen, H. (2008). Determination of students' alternative conceptions about chemical equilibrium: a review of research and the case of Turkey. Chemistry Education Research and Practice, 9(3), 225-233.

Passmore, C. M., \& Svoboda, J. (2012). Exploring opportunities for argumentation in modelling classrooms. International Journal of Science Education, 34(10), 1535-1554.

Patton, M. Q. (2002). Two decades of developments in qualitative inquiry: A personal, experiential perspective. Qualitative social work, 1(3), 261-283.

Potisen P., \&Faikhamta C. (2017). How do I Develop Grade-11 Students' Mental Models in the Rate of Reaction?: Classroom Action Research. J. Res. Unit Sci. Technol. Environ. Learning, 8(1), 101-122. 
Sampson, V., \& Clark, D. (2009). The impact of collaboration on the outcomes ofscientific argumentation. Science education, 93(3), 448-484.

Sanchez, J. M. P. (2018). Translational Skills of Students in Chemistry. Science Education International, 29(4), 214-219.

Schwedler, S., \& Kaldewey, M. (2020). Linking the submicroscopic and symbolic level in physical chemistry: how voluntary simulation-based learning activities foster first-year university students' conceptual understanding. Chemistry Education Research and Practice.

Scott, P., Asoko, H., \& Leach, J. (2007). Student conceptions and conceptual learning. Handbook of research on science education, 31-56.

Siegel, H. (1995). Naturalized epistemology and'first philosophy'. Metaphilosophy, 26(1/2), 46-62.

Srichiangha, C. (2014). Developing grade-11 students' conceptions about chemical equilibrium and attitudes towards chemistry through model-based learning activities, Master thesis, Kasetsart University, Bangkok.

Taber, K. S. (2017). Researching moving targets: studying learning progressions and teaching sequences. Chemistry Education Research and Practice, 18(2), 283-287.

Taber, K. S. (2013). Three levels of chemistry educational research. Chemistry Education Research and Practice, 14(2), 151-155.

Taylor, I., Barker, M., \& Jones, A. (2003). Promoting mental model building in astronomy education. International Journal of Science Education, 25(10), 1205-1225.

Toulmin, S. (1958). The layout of arguments. The uses of argument, 94-145.

Van Der Valk, T., Hackling, J. H., \& De Vos, W. (2007). Common characteristics of models in present-day scientific practice. Research in Science Education, 37(4), 469-488.

Van Driel, J. H., \& Gräber, W. (2002). The teaching and learning of chemical equilibrium. In Chemical education: Towards research-based practice (pp. 271-292): Springer.

Voska, K. W., \& Heikkinen, H. W. (2000). Identification and analysis of student conceptions used to solve chemical equilibrium problems. Journal of Research in Science Teaching: The Official Journal of the National Association for Research in Science Teaching, 37(2), 160-176.

Vosniadou, S. (1994). Capturing and modeling the process of conceptual change. Learning and instruction, 4(1), 45-69.

Vosniadou, S., Skopeliti, I., \& Ikospentaki, K. (2004). Modes of knowing and ways of reasoning in elementary astronomy. Cognitive Development, 19(2), 203-222.

Yakmaci-Guzel, B. (2013). Preservice chemistry teachers in action: an evaluation of attempts for changing high school students' chemistry misconceptions into more scientific conceptiaons. Chemistry Education Research and Practice, 14(1), 95-104. 